\section{Genome ethics treaty}

SIR - The last decade of this century may well be remembered as the true beginning of the era of human gene diagnosis and therapy, but also as a time of confusion and confrontation over the ethical, legal and social implications of the applications of recombinant DNA technology to humans.

These divergences were patent at a conference recently held at the National Institutes of Health on ethical and social issues raised by the human genome project, which failed to reach conclusions about the need for a genome ethics treaty. Yet many participants urged the need for a consensus on fundamental questions. It may be too soon for a detailed code of behaviour, but supranational and national institutions are asking the scientific community for at least some unquestionable guidelines. And much could be done.

For example, in October 1988, what is called the Declaración de Valencia included some general statements proposed by the participants of a Workshop on International Cooperation for the Human Genome Project held in Spain. It says that "mapping and sequencing of the human genome should be only used to increase human dignity". It also urges international coordination on research and information, which should be in the public domain.

Although research should not be stopped, potentially hazardous experimental strategies should be strictly controlled - among them germline as distinct from somatic DNA intervention. The first issue implies a manipulation of the heritable genetic information

\section{Sanctions on Iraq}

SIR - The suggestions by Abdalla $O$. Elkhawad and Scott D. Cobourn (Nature $351,9 ; 1991)$ are not sensible or reasonable. To place a scientific embargo on the Iraqi scientific community would to no good because limiting science would only harm everyone. A better policy would be to establish or maintain contact with the Iraqi scientific community in order to exert influence within Iraq. As an example, Canada's foreign policy towards South Africa comes to mind. At no time did Canada ever sever relations with South Africa. Not only has it maintained an embassy in South Africa, it has also allowed the continued import of South African scientific periodicals and journals to Canadian universities and institutes, as well as permitting trade and other informal contacts to continue.

Box 166, Delta,

KeIth W. Steeves

British Columbia, Canada V4K 3N6 from all cells. This might explain the logical fears raised in Germany because of its potential use in Nazi-like eugenics policies ${ }^{1}$.

On the other hand, nobody can deny the potential benefits of somatic. DNA therapy, as proposed for example for cystic fibrosis by introducing the normal gene into lung cells ${ }^{2}$. The first encouraging results of the applicability of gene therapy in other diseases have recently been demonstrated by in vitro infection of tumour-infiltrating lymphocytes with a retrovirus expressing a selectable marker and their reimplantation into donor cancer patients ${ }^{3}$. That study provides the first clinical data on the safety and efficacy of gene transfer in humans and points to its application to single-gene recessive disorders, where a correction of the endogenous mutant gene is not required.

It now seems appropriate to establish a reference code on somatic cell modification, but more information on the consequences of germline manipulation in experimental models is required before a code for its human application can be determined.

Oscar G. Segurado Institute of Immunology, DOLORES J. SCHENDEL

Goethestrasse 31 ,

8000 Munich 2, Germany

1. Aldhous, P. Nature 351, 507 (1991).

2. Marx, J. L. Science 245, 923-925 (1989)

3. Rosenberg S. A. et al. New Engl. J. Med. 323, 570-578 (1990).

\section{Orange sky . . .}

SIR - Your recent note about ball lightning (Nature 350, 108-109; 1991) mentioned a few sightings by "qualified scientists". I am both a professional and amateur astronomer and an active storm chaser, and wish to describe my recent observation of bead lightning (multiple ball lightning?).

Some doubt is still expressed about the reality of this phenomenon. Afterimages from a bright flash, or chance alignment of lightning segments towards the observer, have been suggested as possible explanations, but the circumstance of my sighting denies these possible explanations.

On the evening of 17 February 1990, I stepped outside to examine the possibility of recording lightning on video. After a short time, there was a brilliant flash behind me and, on spinning round, I saw a 'zig-zag' trail of perhaps 30 small orange balls, quite evenly spaced, outlining the path of the lightning stroke. The balls looked of uniform size, with the higher balls being fainter and of smaller angular diameter. Towards the bottom end, the balls were around half the angular diameter of the Moon.

Another sighting of the same lightning strike was made by people in another house down the street and gave a parallax of nearly $90^{\circ}$. (These witnesses saw no balls, presumably as they were significantly fainter than the lightning stroke.) This indicated a distance of $50 \mathrm{~m}$ from myself and gives an actual size of 15 to $25 \mathrm{~cm}$ for the balls. Examination of the garden and buildings where the strike would have grounded failed to show the precise spot, but the general area of the strike is consistent with damaged appliances in surrounding houses and the tremendous clap of thunder following rapidly after the strike.

The balls showed no motion and faded very rapidly, lasting perhaps 1 second, with no smoke or other remnant at their disappearance. In appearance thev were roughly circular, orange on the outside, brightening towards the centre which I think was white. The integrated brightness of each ball was roughly magnitude -4 , comparable to Venus and certainly much less than the brightness of the full Moon (-13). Despite daylight, it being 7 p.m., the sky was very dark with a total overcast. Coonabarabran, NSW 2357, Australia

\section{Bacon's chicken}

SIR - Your correspondent W. F. J. Cuthbertson attributes the development of refrigeration for preserving food to the invention of the compression expansion refrigerator in 1872 (Nature 351, $434 ; 1991)$. The history of food refrigeration is in fact considerably longer. The principle was certainly used domestically in Europe and North America in the eighteenth century, as shown by the icehouses of great estates in England and the then American colonies, and it was being exploited for the export of perishable goods from New England to Calcutta by 1833 . Exports of ice from Boston exceeded 100,000 tons a year by the mid-nineteenth century ${ }^{1}$.

Credit for the concept of food refrigeration must go to Francis Bacon, Viscount St Albans, whose experiment to preserve a chicken carcass using snow took place at Highgate in 1626. Bacon died of pneumonia three days later ${ }^{2}$. The shelf-life of the chicken is not recorded.

Department of Pharmacology

KENT L. WOODS and Therapeutics,

Centre for Urban History,

ROSE WOODS

The University, Leicester LE2 7LX, UK

1. Boorstin D. J. The Americans 2: The National Experience 22-30 (Penguin, London 1969).

2. Dick O. L. (ed). Aubrey's Brief Lives 124 (Penguin London 1972). 